\title{
Seminar-case learning model improves clinical teaching: A prospective randomized controlled trial
}

\author{
Peiyuan Li ${ }^{1}$, Bin Zeng ${ }^{1}$, Xuanmin Chen ${ }^{1}$, Zhifeng Liu ${ }^{\text {Corresp., }}{ }^{2}$, Jing Yang ${ }^{\text {Corresp. } 1}$ \\ 1 Department of Gastroenterology, The First Affiliated Hospital of University of South China, Hengyang, Hunan, China \\ 2 Department of Otorhinolaryngology, The First Affiliated Hospital of University of South China, Hengyang, Hunan, China \\ Corresponding Authors: Zhifeng Liu, Jing Yang \\ Email address: liuzf@usc.edu.cn, yangjing@usc.edu.cn
}

Purpose. The purpose of this research was to assess whether the efficacy of the seminar-case learning model is superior to the traditional lecture-based learning model in the gastroenterology curriculum for first-year graduate students.

Materials \& Methods. This research was a prospective randomized controlled trial that enrolled 92 first-year postgraduate students with a rotation internship in the gastroenterology department. The students were randomly divided into 2 groups and then subjected to an identical version of the curriculum for 8 weeks. The experimental group $(n=50)$ used the seminar-case learning model, while the control group $(n=42)$ used the traditional lecture-based learning model. Examinations consisted of a theoretical test and a case analysis test, and anonymous questionnaires were used to assess teaching quality.

Results. All participants completed the examinations and questionnaires. The average theoretical test score of the experimental group was no statistical significance with that of the control group $(P=0.17)$. The average case analysis test score of the experimental group was significantly higher than that of the control group $(P<0.05)$. The indicators of the experimental group's feedback were better than those of the control group, such that there were significantly higher learning interest and motivation, a better understanding of diseases and knowledge, improvements in clinical thinking and summary ability, and an active classroom atmosphere in the experimental group $(P<0.05)$. However, students in the experimental group felt more burdensome.

Conclusion. Compared to the traditional method, the seminar-case learning model showed a higher efficacy. The seminar-case learning model effectively improved students' outcomes and satisfaction, which helped students narrow the gap between theoretical knowledge and clinical practical application. 


\section{Seminar-case learning model improves clinical}

2 teaching: a prospective randomized controlled trial

3

4

5

6

7

Peiyuan $\mathrm{Li}^{1}$, Bin Zeng ${ }^{1}$, Xuanmin Chen ${ }^{1}$, Zhifeng Liu ${ }^{2}$ and Jing Yang ${ }^{1}$

${ }^{1}$ Department of Gastroenterology, The First Affiliated Hospital of University of South China, Hengyang, Hunan Province, P.R.China

${ }^{2}$ Department of Otorhinolaryngology, The First Affiliated Hospital of University of South China, Hengyang, Hunan Province, P.R.China

Corresponding Author:

Jing Yang, M.D.

69\# Chuanshan Road, Shigu District Hengyang, Hunan Province, 421001, P.R. China

Email address: yangjing@usc.edu.cn

Zhifeng Liu, M.D.

69\# Chuanshan Road, Shigu District Hengyang, Hunan Province, 421001, P.R. China

Email address: liuzf@usc.edu.cn

\section{Abstract}

Purpose. The purpose of this research was to assess whether the efficacy of the seminar-case learning model is superior to the traditional lecture-based learning model in the gastroenterology curriculum for first-year graduate students.

Materials \& Methods. This research was a prospective randomized controlled trial that enrolled 92 first-year postgraduate students with a rotation internship in the gastroenterology department. The students were randomly divided into 2 groups and then subjected to an identical version of the curriculum for 8 weeks. The experimental group $(n=50)$ used the seminar-case learning model, while the control group $(n=42)$ used the traditional lecture-based learning model. Examinations consisted of a theoretical test and a case analysis test, and anonymous questionnaires were used to assess teaching quality.

Results. All participants completed the examinations and questionnaires. The average theoretical test score of the experimental group was no statistical significance with that of the control group $(\mathrm{P}=0.17)$. The average case analysis test score of the experimental group was significantly higher than that of the control group $(\mathrm{P}<0.05)$. The indicators of the experimental group's feedback were better than those of the control group, such that there were significantly higher learning interest and motivation, a better understanding of diseases and knowledge, improvements in clinical thinking and summary ability, and an active classroom atmosphere in the experimental group $(\mathrm{P}<$ 0.05). However, students in the experimental group felt more burdensome. 
39 Conclusion. Compared to the traditional method, the seminar-case learning model showed a

40 higher efficacy. The seminar-case learning model effectively improved students' outcomes and 41 satisfaction, which helped students narrow the gap between theoretical knowledge and clinical 42 practical application.

43 Introduction

44 With the diversification of education models, advanced medical education with medical students 45 is facing increasing challenges. Traditional lecture-based learning (LBL) is mainly taught by teachers through "lecture teaching". Teachers impart medical knowledge from books to students through a monotonous lecture teaching model, which fails to cultivate independent thinking and practical applications of students (Estai \& Bunt 2016; Zeng et al. 2020). However, most patients have many symptoms with complex conditions and require doctors with clinical practice abilities (Karle 2006; Xiao et al. 2007). Therefore, it is urgent to expand new teaching models and methods to improve the efficacy of clinical teaching.

According to the ICAP framework by Chi et al, learning will increase from passive to active to constructive to interactive(Chi \& Wylie 2014). Learning efficacy is enhanced when students interactively engage in discussions among groups(Chi et al. 2017). A seminar, an effective tool to stimulate discussions, is defined as a class or meeting with an intense exchange of ideas on a particular issue (Skeff et al. 1986). As the center of the learning environment, students can actively analyze clinical problems under the guidance of teachers. The communication between teachers and students enables multiangle interaction to achieve the harmonious unification of "teaching" and "learning" (Spruijt et al. 2012a; Zeng et al. 2020). Case-based learning (CBL) is based on real case scenarios. Teachers provide real cases to arouse the interest of students in learning and to develop the clinical reasoning of the students (Ali et al. 2018; Liu et al. 2020). Thus, teachers can help students narrow the gap between theory and practice (Radomski \& Russell 2010; Thistlethwaite et al. 2012). Case-based learning includes sufficient information and detail to induce active analysis by students, which can improve clinical reasoning skills(Klein et al. 2019; Weidenbusch et al. 2019). However, a systematic review of the effectiveness of case-based learning in health education showed there were few large-sample randomized trials with outcomes of empirical data rather than description(Thistlethwaite et al. 2012). Seminars were well accepted by medical students in evidence-based medicine learning and might led to an increase in knowledge, interestingly with a good effect in transferring knowledge into a paper case scenario(Weberschock et al. 2005).

The seminar-case learning model innovatively integrates the efficient communications of seminar learning and clinical thinking of case-based learning. We hypothesize the seminar-case learning model can improve ef cacy of clinical teaching and satisfy students compared to traditional lecture-based learning. There are few large-sample randomized synthesis trials of the two methods in clinical teaching. We may provide data by prospective evaluation and randomized experimental design.

The purpose of this study was to assess whether the ef cacy of the seminar-case learning model was superior to that of the traditional lecture-based learning model among first-year postgraduate students in the gastroenterology curriculum. We performed a randomized study to compare seminar-case learning with traditional lecture-based learning. 


\section{Materials \& Methods}

83 Participation and groups

84 Based on the inclusion criteria, the trial enrolled 92 first-year postgraduate students specializing 85 in clinical internal medicine with a rotation internship in the gastroenterology department of The 86 First Affiliated Hospital of University of South China from January 2019 to December 2019. Oral 87 informed consent was obtained from all students. Decisions about whether to participate did not 88 influence their grades. All participants had already been granted an undergraduate degree from a 89 medical university. All participants were randomly divided into an experimental group (50 90 students) and a control group (42 students). Our study was approved by The Ethics Committee of 91 the First Affiliated Hospital of University of South China (No. NHFY201973).

92 Design

93 The curriculum contents of the experimental group and the control group were identical and 94 included common diseases in the gastroenterology section of the 8th edition of the Internal 95 Medicine textbook, including gastroesophageal reflux disease, peptic ulcer, intestinal tuberculosis, 96 inflammatory bowel disease, functional gastrointestinal disorder, liver cirrhosis, acute pancreatitis, 97 and gastrointestinal hemorrhage bleeding, which were lectured by 2 leading teachers separately. 98 The experimental groups used the seminar-case learning model, while the control groups used the 99 traditional lecture model. These two groups also underwent 8 weeks of rotation study in the 100 gastroenterology department simultaneously. We arranged the curriculum of the experimental 101 group and the control group on different days once a week (Monday and Thursday, respectively). 102 The students in the experimental group and the control group were also arranged in different wards 103 ground ( 2 floors of wards) to avoid contamination between groups.

104 The experimental group used the seminar-case learning model as follows:

\section{Case selection}

106 A vice chief physician worked as the lead teacher, and a resident physician served as the assistant 107 teacher. According to a specific disease of the internal medicine textbook outline, the leading 108 teacher selected a typical patient hospitalized in the gastroenterology department as the teaching 109 case. The assistant teacher liaised with the patients and obtained their permission 3 days before the 110 class. With the agreement of the selected patients, the assistant teacher sent the patient's 111 anonymized information, including their chief history, daily activities, past history, and results of 112 clinical examinations, to students in a newly established WeChat group. The leading teacher raised 113 some questions about the disease's diagnosis and treatments in advance.

\section{Preparation work}

115 Students were expected to collect the relevant literature and the latest guidelines based on the 116 clinical data of the selected case. Students were divided into groups of 4-5 people before class. 117 Each group organized materials and prepared answers to questions.

\section{Seminar-case learning model}

119 The assistant teacher helped the leading teacher provide the learning material and teaching 120 equipment for the experiment group. First, the leading teacher gave a brief lecture (10-15 minutes) 121 to illustrate the main points of disease, of which the content was a simplified version of traditional 
122 teaching. Then, the leading teacher introduced the selected case. In a seminar, students summarized

123 the disease characteristics and analyzed the results of patients' clinical auxiliary examinations in

124 groups. Students were required to answer preview questions. During this course, the leading

125 teacher discussed with grouped students freely and corrected their answers. Finally, the leading

126 teacher summarized the clinical characteristics of the case and extended the case to the disease,

127 and shared experience with the disease. PowerPoint was used to show the context of the lecture

128 and anonymous patient information as well as the materials of the course. The whole teaching time

129 of each course was 90 min once a week.

130 The control group used traditional lecture learning as follows:

131 The learning material and teaching equipment for the control group were also provided by the 132 assistant teacher. The same leading teacher from the experimental group gave one lecture by 133 PowerPoint based on contents of the gastroenterology section of the 8th edition Internal Medicine

134 Textbook and shared experiences with the disease, but with no discussion or case. The leading 135 teacher proposed the same questions and analyzed and answered these questions in the class. The

136 teacher also answered the students' questions after class. The whole teaching time of each course 137 was 90 min once a week, the same as the experiment group. We controlled for the potential variable

138 factors in both the experimental and control groups by the assistant teacher, including the same 139 setting, video assistance, and a corresponding simplified PowerPoint of the teaching context for 140 the experimental group.

141 Assessment of teaching quality

142 After 8 weeks of rotation practice, the experimental group and the control group underwent the 143 same examinations and responded to an anonymous questionnaire at the same time. The 144 examinations included a theoretical examination and a case analysis examination with a total score 145 of 100 points. All test papers and questionnaires were prepared, graded, and recorded by the 146 teaching supervisor of Gastroenterology.

\section{Theoretical examination}

148 The regular theoretical examination includes 5 questions: 1 . What are the common causes of 149 gastrointestinal bleeding? 2. What are the clinical manifestations of decompensated liver cirrhosis?

150 3. What are the treatments for peptic ulcers? 4. What are the diagnostic criteria for ulcerative 151 colitis? 5. What are the diagnostic criteria for acute pancreatitis? The total score was 100 points, 152 with 20 points for each question.

\section{Case analysis}

154 Two new cases were presented to the students in test papers. Students were required to answer the

155 key points of the diagnosis and treatments of the disease related to the case in a written form. The 156 total score was 100 points, with 50 points for each case.

\section{Questionnaire}

158 The questionnaire included 9 items on students' feelings and perceptions of their classes. Students 159 filled in a table with a "yes" or "no" after each item in the questionnaire, depending on their 160 perceptions of whether the class had strengthened their various abilities and their fondness of the 161 class. 


\section{Statistical analysis}

163 SPSS 24.0 statistical software was used for data input and statistical analysis. Statistical graphics

164 were completed by GraphPad Prism 8.2.0. The measurement data were expressed as the mean \pm 165 standard deviation $(\overline{\mathbf{X}} \pm \mathbf{S})$. The normal distribution of the data was assessed by the Kolmogorov166 Smirnov test (K-S test). If the data were normally distributed, the independent samples t-test was 167 used to compare the experimental group and the control group; if the data were not normally 168 distributed, the Mann-Whitney rank-sum test was used. The categorical data were analyzed by

169 Pearson's chi-square test to compare the difference in gender and the students' opinions about the teaching methods in two groups. $\mathrm{P}<0.05$ indicated statistical significance.

\section{Results}

173 All 92 participants underwent examinations after 8 weeks of rotation. A total of 50 students were in the experimental group, including 23 males and 27 females. A total of 42 students were in the control group, including 20 males and 22 females. There was no statistically significant difference in gender, age, or entrance exam score between the two groups (Table 1). average theoretical test score of the experimental group was no statistical significance with that of the control group. The case analysis score of the experimental group was significantly higher than that of the control group (Table 2). Forty-two people in the control group and 50 people in the experimental group completed the anonymous questionnaire, and a total of 92 questionnaires were received. The indicators of the experimental group's teaching effect were better than those of the control group, such that there were significant increases in learning interest and motivation, a better understanding of diseases and knowledge, an improvement in clinical thinking and summary ability, and an active classroom atmosphere $(\mathrm{P}<0.05)$. However, some negative learning experiences were reported. Some students thought a seminar-case learning model class had taken up too much spare time and led to stress, which weighted the gains on balance. The survey showed that the majority of students hoped to adopt a seminar-case learning model (Table 3 ).

\section{Discussion}

Traditional teaching is teacher-centered lecture-based learning, which emphasizes the delivery of syllabus and concepts (Barrett et al. 2015). Clinical teaching is usually a retelling of the theoretical content of medical textbooks and ignores the cultivation of students' clinical thinking as well as the practical application of clinical theoretical knowledge to some extent (Singh et al. 2017). Students have poor enthusiasm for dull theoretical knowledge in lecture-based learning (Mahler et al. 2018). Due to patients' diverse clinical symptoms and complicated conditions in realistic cases, the traditional medical teaching model cannot satisfy the practical training needs of medical students (Cleland 2018; Formenti et al. 2015; Schmidt \& Mamede 2015).

In our study, the seminar-case learning model that organically combines theoretical knowledge 
202 by the seminar-case learning model, and satisfactory feelings about the class were improved 203 according to the questionnaire. The improved learning effect may have occurred due to the 204 following reasons. First, students are active and self-learning in the preparation work, including 205 browsing the literature online and previewing knowledge. Second, in seminar discussions, the exchange of ideas between the groups deepens the understanding of clinical issues and promotes the full activation of knowledge structures such as divergent thinking and critical thinking due to the questions between teachers and students. Seminars, as a powerful learning environment, improve students' ability to diagnose and analyze diseases. Third, through the analysis of the selected real cases of patients, students simulated and participated in the entire medical process of patients, taking patient symptoms and signs as a starting point, obtaining specific clinical examination results, and carrying out diagnosis and treatment, thus promoting the practical application of theoretical knowledge. Furthermore, clinical thinking was cultivated in the process of seminar discussion and case learning. Notably, the efficacy of teaching outcomes is higher in the study group, considering an equal amount of hours invested by the teachers, costs, the equivalence of equipment and room space.

Our research found some interesting negative results. Although the average score of the experimental group is higher than that of the control group, there was no statistically significant difference in the theoretical test score between the two groups, which may be explained by selflearning and textbook review after class. Furthermore, some students thought seminar-case learning model occupied more time and was made a burden by the preparation work of relevant literature and the latest guidelines of the relative case. This negative learning experience may be improved by choosing relatively simpler cases and simplifying the preparation work. Comfortingly, $70 \%(35 / 50)$ of the experimental group tended to the seminar-case learning model.

A seminar is a class at a college or university in which the teacher and a small group of students discuss a topic interactively (Runquist et al. 2006). In previous research, the seminar method has been shown to an effective and feasible way to improve clinical teaching (Skeff et al. 1986; Takata et al. 2013). Seminar-based teaching greatly increases students' learning motivation. The mutual communications between teachers and students not only consolidate theoretical knowledge but also expands students' horizons (Landry et al. 1994). Moreover, seminars turn the "lecture style" into a "discussion style", making the teaching atmosphere lively and relaxed, democratic, and equal, thus increasing students' enthusiasm and intention to learn (Spruijt et al. 2012b).

Case-based learning combines clinical theoretical knowledge with real patient cases (Dickinson 234 et al. 2018; Thistlethwaite et al. 2012). In our study, students needed to find clues from the limited information of the cases and finally make the diagnosis and treatment plan based on the patient's symptoms, signs, and auxiliary examinations in the real case. In the process of simulated diagnosis and treatment, teachers encouraged students to think logically and critically to put clinical theoretical knowledge into practice (Edelbring et al. 2012a; Edelbring et al. 2012b; Weidenbusch et al. 2019). Similarly, students' ability to analyze and solve clinical problems was fully cultivated to better apply their theoretical knowledge to clinical use (Dickinson et al. 2018; Liu et al. 2020). 
261

262

263

264

265

266

267

268

269

270

271

272

273

274

275

276

277

278

279

280

281

282

In our research, the seminar-case learning model made full use of its advantages in teaching and achieved better effects than the traditional model. However, there were still some limitations in this prospective study. First, although the course content was the same between the two groups, there were minor differences in teaching PowerPoint slides. We were not able to determine whether these minor differences influenced the results. Moreover, courses in both groups were introduced by one lead teacher to eliminate bias due to teaching level. This means that doubleblinding was not possible, which may have affected the validity of the findings. Notably, students in the experimental group were likely to spend more time studying after class, which can not be accurately counted in the experimental design and may result in a deviation in efficacy. The superiority of the seminar-case learning model should be supported by more randomized controlled data from diverse departments in multiple teaching hospitals.

\section{Conclusions}

In general, our study applies the seminar-case learning model to clinical teaching in the gastroenterology department. Compared to the traditional method, the seminar-case learning model showed a higher efficacy, which demonstrated better outcomes and feedback compared to the traditional method. The seminar-case learning model combined lecture teaching and discussion based on real cases, realizing the integration of theoretical knowledge and clinical practical application and exerting a profound impact on medical education. The seminar-case learning model, as an effective method for high-quality education, can be adopted by educators.

\section{Acknowledgments}

We would like to thank our colleagues in the graduate administration office and the medical teaching and research department for administrative and academic support. We would also like to thank all postgraduates enrolled in this study.

\section{References}

Ali M, Han SC, Bilal HSM, Lee S, Kang MJY, Kang BH, Razzaq MA, and Amin MB. 2018. iCBLS: An interactive case-based learning system for medical education. International journal of medical informatics 109:55-69. 10.1016/j.ijmedinf.2017.11.004

Barrett J, Yates L, and McColl G. 2015. Medical teachers conceptualize a distinctive form of clinical knowledge. Advances in health sciences education : theory and practice 20:355369. 10.1007/s10459-014-9532-6

Chi MTH, Kang S, and Yaghmourian DL. 2017. Why Students Learn More From Dialogue- Than Monologue-Videos: Analyses of Peer Interactions. Journal of the Learning Sciences 26:10-50. 10.1080/10508406.2016.1204546

Chi MTH, and Wylie R. 2014. The ICAP Framework: Linking Cognitive Engagement to Active Learning Outcomes. Educational Psychologist 49:219-243. 10.1080/00461520.2014.965823

Cleland J. 2018. The Medical School Admissions Process and Meeting the Public's Health Care Needs: Never the Twain Shall Meet? Academic medicine : journal of the Association of American Medical Colleges 93:972-974. 10.1097/ACM.0000000000002104 
283

284

285

286

287

288

289

290

291

292

293

294

295

296

297

298

299

300

301

302

303

304

305

306

307

308

309

310

311

312

313

314

315

316

317

318

319

320

321

322

323

324

325

326

327

328

329

330

331

332

Dickinson BL, Lackey W, Sheakley M, Miller L, Jevert S, and Shattuck B. 2018. Involving a real patient in the design and implementation of case-based learning to engage learners. Adv Physiol Educ 42:118-122. 10.1152/advan.00174.2017

Edelbring S, Brostrom O, Henriksson P, Vassiliou D, Spaak J, Dahlgren LO, Fors U, and Zary N. 2012a. Integrating virtual patients into courses: follow-up seminars and perceived benefit. Medical Education 46:417-425. 10.1111/j.1365-2923.2012.04219.x

Edelbring S, Brostrom O, Henriksson P, Vassiliou D, Spaak J, Dahlgren LO, Fors U, and Zary N. 2012b. Integrating virtual patients into courses: follow-up seminars and perceived benefit. Med Educ 46:417-425. 10.1111/j.1365-2923.2012.04219.x

Estai M, and Bunt S. 2016. Best teaching practices in anatomy education: A critical review. Annals of anatomy $=$ Anatomischer Anzeiger : official organ of the Anatomische Gesellschaft 208:151-157. 10.1016/j.aanat.2016.02.010

Formenti SC, Bonner JF, Hahn SM, Lawrence TS, Liu F-F, and Thomas CR. 2015. Raising the next generation of physician-scientists: the chairs' perspective. International journal of radiation oncology, biology, physics 92:211-213. 10.1016/j.jijobp.2015.01.038

Karle H. 2006. Global standards and accreditation in medical education: a view from the WFME. Academic medicine : journal of the Association of American Medical Colleges 81:S43S48.

Klein M, Otto B, Fischer MR, and Stark R. 2019. Fostering medical students' clinical reasoning by learning from errors in clinical case vignettes: effects and conditions of additional prompting procedures to foster self-explanations. Advances in health sciences education : theory and practice 24:331-351. 10.1007/s10459-018-09870-5

Landry FJ, Pangaro L, Kroenke K, Lucey C, and Herbers J. 1994. A controlled trial of a seminar to improve medical student attitudes toward, knowledge about, and use of the medical literature. Journal of general internal medicine 9:436-439.

Liu Y, Xu Y, Li Y, and Wu Q. 2020. Application of problem-based learning and case-based learning integrated method in the teaching of maxillary sinus floor augmentation in implant dentistry. PeerJ 8:e8353. 10.7717/peerj.8353

Mahler D, Großschedl J, and Harms U. 2018. Does motivation matter? - The relationship between teachers' self-efficacy and enthusiasm and students' performance. PloS one 13:e0207252. 10.1371/journal.pone.0207252

Radomski N, and Russell J. 2010. Integrated case learning: teaching clinical reasoning. Advances in health sciences education : theory and practice 15:251-264. 10.1007/s10459-009-9195-X

Runquist JJ, Kerns RD, Fee SS, Choi M, and Glittenberg J. 2006. A co-created learning process in a doctoral seminar. The Journal of nursing education 45:32-34. 10.3928/0148483420060101-06

Schmidt HG, and Mamede S. 2015. How to improve the teaching of clinical reasoning: a narrative review and a proposal. Medical Education 49:961-973. 10.1111/medu.12775

Singh H, Schiff GD, Graber ML, Onakpoya I, and Thompson MJ. 2017. The global burden of diagnostic errors in primary care. BMJ quality \& safety 26:484-494. 10.1136/bmjqs-2016005401

Skeff KM, Stratos G, Campbell M, Cooke M, and Jones HW. 1986. Evaluation of the seminar method to improve clinical teaching. Journal of general internal medicine 1:315-322.

Spruijt A, Jaarsma AD, Wolfhagen HA, van Beukelen P, and Scherpbier AJ. 2012a. Students' perceptions of aspects affecting seminar learning. Medical teacher 34:e129-135. 10.3109/0142159x.2012.644829

Spruijt A, Jaarsma AD, Wolfhagen HA, van Beukelen P, and Scherpbier AJ. 2012b. Students' perceptions of aspects affecting seminar learning. Med Teach 34:e129-135. 10.3109/0142159x.2012.644829

Peer) reviewing PDF | (2020:06:49934:3:1:NEW 5 Apr 2021) 
333

334

335

336

337

338

339

340

341

342

343

344

345

346

347

348

349

350

351

352

353

354

355

356

357

358

359

Table 2. Comparison of average scores between the two groups $\left({ }_{x}^{-} \pm s\right)$

\begin{tabular}{|c|c|c|c|c|}
\hline \multirow[t]{2}{*}{$\square$} & \multirow{2}{*}{$\begin{array}{l}\text { Control } \\
\text { group } \\
\mathrm{n}=\mathbf{4 2}\end{array}$} & \multicolumn{2}{|c|}{ Experimental group } & \multirow{2}{*}{$\begin{array}{l}\square \text { value } \\
\square\end{array}$} \\
\hline & & $\mathrm{n}=\mathbf{5 0}$ & t value & \\
\hline Theoretical test scores & $82.45 \pm 6.38$ & $84.3 \pm 6.42$ & 1.3800 & 0.1711 \\
\hline $\begin{array}{l}\begin{array}{l}\text { Case } \\
\text { scores }\end{array} \\
\text { analysis test }\end{array}$ & $80.79 \pm 7.12$ & $85.52 \pm 4.82$ & 3.7820 & 0.0003 \\
\hline
\end{tabular}

360

Table 3. Comparison of questionnaire results between the two groups

Takata Y, Stein GH, Endo K, Arai A, Kohsaka S, Kitano Y, Honda H, Kitazono H, Tokunaga H, Tokuda Y, Obika M, Miyoshi T, Kataoka H, and Terasawa H. 2013. Content analysis of medical students' seminars: a unique method of analyzing clinical thinking. BMC medical education 13:156. 10.1186/1472-6920-13-156

Thistlethwaite JE, Davies D, Ekeocha S, Kidd JM, MacDougall C, Matthews P, Purkis J, and Clay D. 2012. The effectiveness of case-based learning in health professional education. A BEME systematic review: BEME Guide No. 23. Medical teacher 34:e421-e444. 10.3109/0142159X.2012.680939

Weberschock TB, Ginn TC, Reinhold J, Strametz R, Krug D, Bergold M, and Schulze J. 2005. Change in knowledge and skills of Year 3 undergraduates in evidence-based medicine seminars. Medical Education 39:665-671. 10.1111/j.1365-2929.2005.02191.x

Weidenbusch M, Lenzer B, Sailer M, Strobel C, Kunisch R, Kiesewetter J, Fischer MR, and Zottmann JM. 2019. Can clinical case discussions foster clinical reasoning skills in undergraduate medical education? A randomised controlled trial. BMJ open 9:e025973. 10.1136/bmjopen-2018-025973

Xiao H, Xian L, Yu X, and Wang J. 2007. Medical curriculum reform in Sun Yat-sen University: implications from the results of GMER evaluation in China. Medical teacher 29:706-710. 10.1080/01421590701713579

Zeng HL, Chen DX, Li Q, and Wang XY. 2020. Effects of seminar teaching method versus lecture-based learning in medical education: A meta-analysis of randomized controlled trials. Med Teach:1-7. 10.1080/0142159X.2020.1805100

Table 1. Comparison of general data between two groups of students

\begin{tabular}{llllc}
\hline \multirow{2}{*}{ Group } & \multicolumn{2}{c}{ Sex } & Age/year & $\begin{array}{l}\text { Entrance exam } \\
\text { score }\end{array}$ \\
\cline { 2 - 5 } & Male & Female & & 79.43 \\
\hline Control group & 15 & 27 & $24.48 \pm 1.93$ & 80.6 \\
Experimental group & 22 & 28 & $24.38 \pm 1.91$ & 0.7800 \\
$t$ value/ $\chi 2$ & 0.3527 & & 0.2390 & 0.4363 \\
$p$ value & 0.5526 & $\square$ & 0.8116 & \\
\hline
\end{tabular}

\begin{tabular}{lllll}
\hline Items surveyed & Experiment & Control & $\chi^{2}$ & $p$ value \\
\cline { 3 - 4 }
\end{tabular}




\begin{tabular}{|c|c|c|c|c|c|c|}
\hline & \multicolumn{2}{|c|}{$\begin{array}{c}\text { al group } \\
\mathbf{n}=\mathbf{5 0}\end{array}$} & \multicolumn{2}{|c|}{$\begin{array}{c}\text { group } \\
n=42\end{array}$} & & \\
\hline & Yes & No & Yes & No & & \\
\hline Increase learning interest and motivation & 37 & 13 & 17 & 25 & 9.2436 & 0.0024 \\
\hline $\begin{array}{l}\text { Better understanding of diseases and } \\
\text { knowledge }\end{array}$ & 36 & 14 & 18 & 24 & 6.8395 & 0.0089 \\
\hline $\begin{array}{l}\text { Improve communication and expression } \\
\text { skills }\end{array}$ & 28 & 22 & 15 & 27 & 3.0024 & 0.0831 \\
\hline Develop teamwork ability & 26 & 24 & 16 & 26 & 1.2625 & 0.2612 \\
\hline Improve self-learning ability & 30 & 20 & 16 & 26 & 3.5486 & 0.0596 \\
\hline $\begin{array}{l}\text { Cultivate clinical thinking and summary } \\
\text { ability }\end{array}$ & 38 & 12 & 10 & 32 & 22.8693 & $<0.0001$ \\
\hline Activate the classroom atmosphere & 39 & 11 & 11 & 31 & 22.6509 & $<0.0001$ \\
\hline Occupy time and make a burden & 37 & 13 & 15 & 27 & 12.1016 & 0.0005 \\
\hline Continue to adopt this teaching method & 35 & 15 & 14 & 28 & 10.8989 & 0.0010 \\
\hline
\end{tabular}

362 Figure 1. Theoretical test scores and case analysis test scores of the two groups

363 Figure legend. A, theoretical test scores of the two groups; B, case analysis test scores of the two

364 groups (the control group: $\mathrm{n}=42$; the experimental group: $\mathrm{n}=50$ ) 


\section{Table $\mathbf{1}$ (on next page)}

Table 1 Comparison of general data between two groups of students. Table 2

Comparison of average scores between two groups of students. Table 3 Comparison of questionnaire results between two groups of students. 
1 Table 1. Comparison of general data between two groups of students

\begin{tabular}{llllc}
\hline \multirow{2}{*}{ Group } & \multicolumn{2}{c}{ Sex } & Age/year & $\begin{array}{l}\text { Entrance exam } \\
\text { score }\end{array}$ \\
\cline { 2 - 5 } & Male & Female & & 79.43 \\
\hline Control group & 15 & 27 & $24.48 \pm 1.93$ & 80.6 \\
Experimental group & 22 & 28 & $24.38 \pm 1.91$ & 0.7800 \\
t value/ $\chi 2$ & 0.3527 & & 0.2390 & 0.4363 \\
$p$ value & 0.5526 & $\square$ & 0.8116 & \\
\hline
\end{tabular}

2

3 Table 2. Comparison of average scores between the two groups $\left({ }_{x}^{-} \pm s\right)$

\begin{tabular}{lllll}
\hline$\square$ & Control group & \multicolumn{2}{l}{ Experimental group } & $\square$ \\
& $\mathrm{n}=42$ & $\mathrm{n}=50$ & $\mathrm{t}$ value & $p$ value \\
\hline Theoretical test scores & $82.45 \pm 6.38$ & $84.3 \pm 6.42$ & 1.3800 & 0.1711 \\
Case analysis test scores & $80.79 \pm 7.12$ & $85.52 \pm 4.82$ & 3.7820 & 0.0003 \\
\hline
\end{tabular}

4 Table 3. Comparison of questionnaire results between the two groups

\begin{tabular}{|c|c|c|c|c|c|c|}
\hline \multirow[t]{2}{*}{ Items surveyed } & \multicolumn{2}{|c|}{$\begin{array}{c}\text { Experimental } \\
\text { group } \\
n=50\end{array}$} & \multicolumn{2}{|c|}{$\begin{array}{l}\text { Control } \\
\text { group } \\
n=42\end{array}$} & \multirow[t]{2}{*}{ c2 } & \multirow[t]{2}{*}{$p$ value } \\
\hline & Yes & No & Yes & No & & \\
\hline Increase learning interest and motivation & 37 & 13 & 17 & 25 & 9.2436 & 0.0024 \\
\hline $\begin{array}{l}\text { Better understanding of diseases and } \\
\text { knowledge }\end{array}$ & 36 & 14 & 18 & 24 & 6.8395 & 0.0089 \\
\hline Improve communication and expression skills & 28 & 22 & 15 & 27 & 3.0024 & 0.0831 \\
\hline Develop teamwork ability & 26 & 24 & 16 & 26 & 1.2625 & 0.2612 \\
\hline Improve self-learning ability & 30 & 20 & 16 & 26 & 3.5486 & 0.0596 \\
\hline $\begin{array}{l}\text { Cultivate clinical thinking and summary } \\
\text { ability }\end{array}$ & 38 & 12 & 10 & 32 & 22.8693 & $<0.0001$ \\
\hline Activate the classroom atmosphere & 39 & 11 & 11 & 31 & 22.6509 & $<0.0001$ \\
\hline Occupy time and make a burden & 37 & 13 & 15 & 27 & 12.1016 & 0.0005 \\
\hline Continue to adopt this teaching method & 35 & 15 & 14 & 28 & 10.8989 & 0.0010 \\
\hline
\end{tabular}

5

6 Figure 1. Theoretical test scores and case analysis test scores of the two groups

7 Figure legend. A, theoretical test scores of the two groups; B, case analysis test scores of the two

8 groups (the control group: $\mathrm{n}=42$; the experimental group: $\mathrm{n}=50$ )

9 
Figure 1

Figure 1. Theoretical test scores and case analysis test scores of the two groups

Figure legend. A, theoretical test scores of the two groups; $B$, case analysis test scores of the two groups (the control group: $n=42$; the experimental group: $n=50$ )
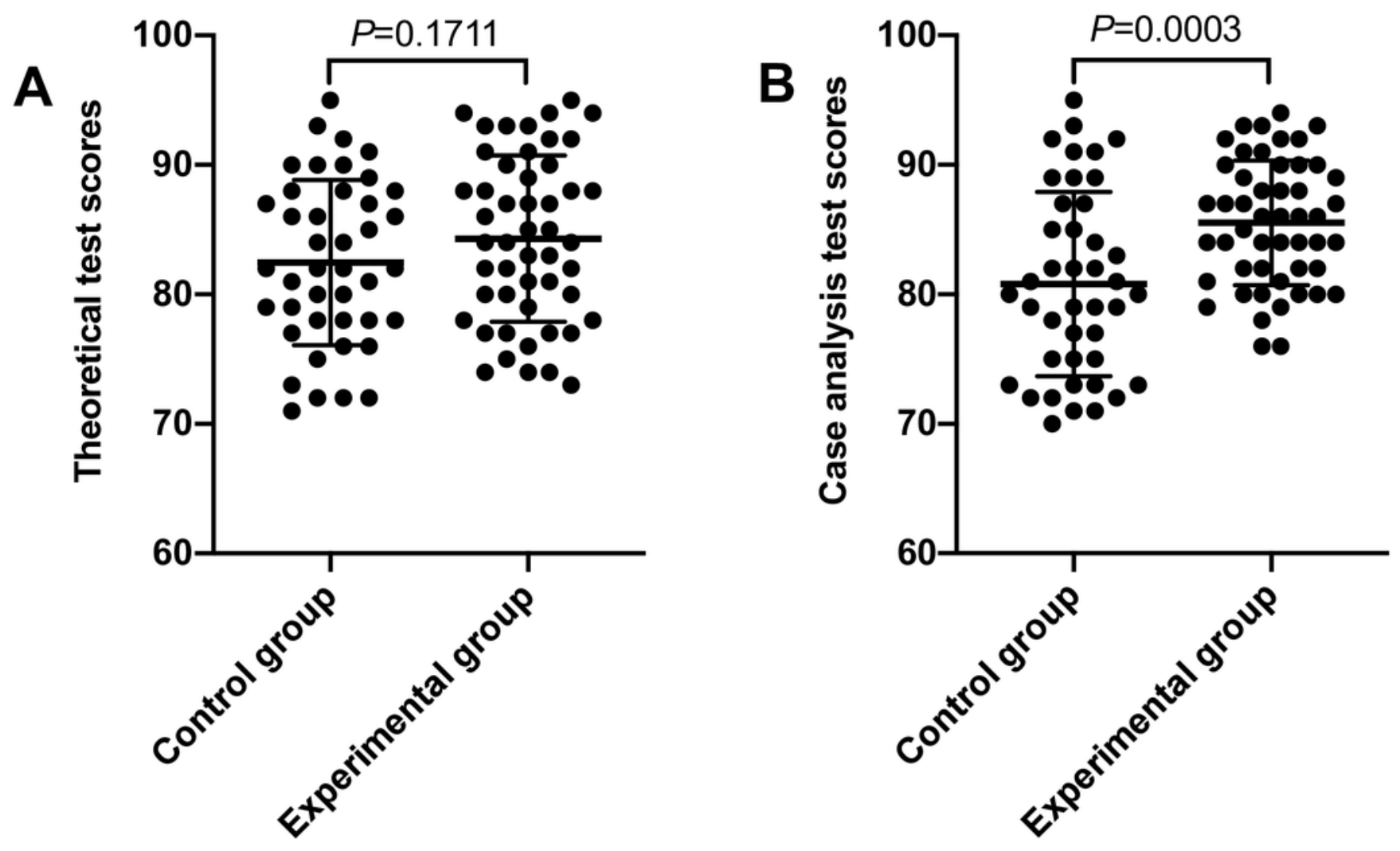